A Method to Site-Specifically Identify and Quantitate Carbonyl End Products of Protein Oxidation Using Oxidation-Dependent Element Coded Affinity Tags (O-ECAT) and NanoLiquid Chromatography Fourier Transform Mass Spectrometry

Susan Lee, Nicolas L. Young, Paul A. Whetstone, Sarah M. Cheal, W. Henry Benner, Carlito B. Lebrilla, Claude F. Meares

August 31, 2005

Journal of Proteome Research 
This document was prepared as an account of work sponsored by an agency of the United States Government. Neither the United States Government nor the University of California nor any of their employees, makes any warranty, express or implied, or assumes any legal liability or responsibility for the accuracy, completeness, or usefulness of any information, apparatus, product, or process disclosed, or represents that its use would not infringe privately owned rights. Reference herein to any specific commercial product, process, or service by trade name, trademark, manufacturer, or otherwise, does not necessarily constitute or imply its endorsement, recommendation, or favoring by the United States Government or the University of California. The views and opinions of authors expressed herein do not necessarily state or reflect those of the United States Government or the University of California, and shall not be used for advertising or product endorsement purposes. 
A Method to Site-Specifically Identify and Quantitate Carbonyl End Products of Protein Oxidation Using Oxidation-Dependent Element Coded Affinity Tags (O-ECAT) and NanoLiquid Chromatography Fourier Transform Mass Spectrometry

Susan Lee ${ }^{* * *}$, Nicolas L. Young ${ }^{* * *}$, Paul A. Whetstone $e^{*}$ Sarah M. Cheal ${ }^{*}$, W. Henry Benner ${ }^{*}$, Carlito B. Lebrilla ${ }^{7^{*}}$, Claude F. Meares ${ }^{\text {t* }^{*}}$

† University of California, Davis, Department of Chemistry, Davis, CA

$\dagger$ Lawrence Livermore National Laboratory, Biosecurity and NanoSciences Laboratory, Livermore, $\mathrm{CA}$

*Corresponding Authors: cblebrilla@ucdavis.edu/cfmeares@ucdavis.edu

** These authors contributed equally to this work

\section{RECEIVED DATE}

TITLE RUNNING HEAD (Word Style “AF_Title_Running_Head”). If you are submitting your paper to a journal that requires a title running head (condensed title appearing at the top of the journal page), please provide a 50-character or less summary of the title of the manuscript. 
$\begin{array}{lllll}\text { CORRESPONDING AUTHOR } & \text { FOOTNOTE } & \text { (Word } & \text { Style }\end{array}$

"FA_Corresponding_Author_Footnote"). Clarify all corresponding authors' addresses by accompanying footnotes if they are not apparent from the affiliation line. Telephone numbers, fax numbers, and e-mail addresses may all be included in the corresponding author footnotes. If an author's address is different than the one given in the affiliation line, this information may also be included here.

\section{ABSTRACT}

Protein oxidation is linked to cellular stress, aging, and disease. Protein oxidations that result in reactive species are of particular interest, since these reactive oxidation products may react with other proteins or biomolecules in an unmediated and irreversible fashion, providing a potential marker for a variety of disease mechanisms. We have developed a novel system to identify and quantitate, relative to other states, the sites of oxidation on a given protein. A specially designed Oxidation-dependent carbonyl-specific Element-Coded Affinity Mass Tag (O-ECAT), AOD, ((S)-2-(4-(2-aminooxy)acetamido)-benzyl)-1, 4, 7, 10-tetraazacyclododecane- $N, N^{\prime}, N^{\prime \prime}, N^{\prime \prime \prime}$-tetraacetic acid, is used to covalently tag the residues of a protein oxidized to aldehyde or keto end products. After proteolysis, the resulting AOD-tagged peptides are affinity purified, and analyzed by nanoLC-FTICR-MS, which provides high specificity in extracting co-eluting AOD mass pairs with a unique mass difference and affords relative quantitation based on isotopic ratios. Using this methodology, we have mapped the surface oxidation sites on a model protein, recombinant human serum albumin (rHSA) in its native form (as purchased) and after FeEDTA oxidation. A variety of modified amino acid residues including lysine, arginine, proline, histidine, threonine, aspartic and glutamic acids, were 
found to be oxidized to aldehyde and keto end products. The sensitivity of this methodology is shown by the number of peptides identified, twenty peptides on the native protein and twenty-nine after surface oxidation using FeEDTA and ascorbate. All identified peptides map to the surface of the HSA crystal structure validating this method for identifying oxidized amino acids on protein surfaces. In relative quantitation experiments between FeEDTA oxidation and native protein oxidation, identified sites showed different relative propensities towards oxidation independent of amino acid residue. We expect to extend this methodology to study disease-related oxidation systems.

KEYWORDS protein oxidation, mass tag, element-coded affinity tag (ECAT), nanoLCFTICR-MS

Abbreviations: rHSA, recombinant human serum albumin; DOTA, 1, 4, 7, 10tetraazacyclododecane- $N, N^{\prime}, N^{\prime \prime}, N^{\prime \prime \prime}$-tetraacetic acid; AOD, ((S)-2-(4-(2-aminooxy)acetamido)-benzyl)-DOTA; M, rare earth element; DIPCDI, diisopropylcarbodiimide; FeEDTA, iron (III) ethylenediaminetetraacetic acid; nanoLC-FTICR-MS, nanoflow liquid chromatography-Fourier transform ion cyclotron resonance-mass spectrometry; DMF, N, N-dimethylformamide; TBS, $24.8 \mathrm{mM}$ Tris, $137 \mathrm{mM} \mathrm{NaCl}, 0.269 \mathrm{mM} \mathrm{KCl,} \mathrm{pH}$ 7.4; TBST, TBS with $0.05 \%$ Tween-20; AP, alkaline phosphatase; HSA, human serum albumin; MS, mass spectrometry; NBD, (S)-2-(4-nitro-benzyl)-DOTA; TEAOAc, triethylammonium acetate. 
BRIEFS (WORD Style "BH_Briefs"). If you are submitting your paper to a journal that requires a brief, provide a one-sentence synopsis for inclusion in the Table of Contents. 


\section{INTRODUCTION}

Protein oxidation has been implicated in cellular stress, aging, and disease ${ }^{1-3}$. In these systems, many different types of oxidative protein modifications, such as cysteine and methionine oxidation, nitration of tyrosine residues, or aldehyde formation from oxidation of lysine, arginine, glutamate, aspartate or proline, may occur ${ }^{1,4-6}$. Of particular interest are the side chain oxidations that result in reactive carbonyl groups due to their reactivity and potential deleterious effects in biological systems. Carbonyls are known protein cross-linking agents ${ }^{7}$ and markers for protein degradation. When cellular protein degradation pathways fail, these species may react with other biomolecules in an unmediated manner potentially forming aggregates of cross-linked biomolecules ${ }^{7}$. Protein aggregation is observed as a morphological change in some oxidation linked diseases such as Alzheimer's disease ${ }^{2}$. Aldehyde and ketone groups are also particularly well-suited for use as markers of protein oxidation because they are relatively stable and present in detectable amounts in tissues ${ }^{1}$. They have also been shown to be the major products of metal-catalyzed oxidation of surface residues lysine and arginine ${ }^{8}$.

Current methods used to study protein oxidation either visualize oxidized proteins using an oxidation-dependent tag or identify oxidation sites using mass spectrometry. The most commonly used derivatization agent to detect oxidation is $2,4-$

dinitrophenylhydrazine (DNPH). DNPH can be used in UV studies of protein oxidation or in combination with an anti-DNPH antibody to visualize proteins using Western blotting $^{9}$. This results in identification of the oxidized proteins but does not give information about the specific oxidation site. The DNPH assay can also be problematic due to the poor solubility of DNPH in aqueous buffers and chromophore contamination ${ }^{10}$. 
Mass spectrometry has been used to detect specific amino acid oxidation through the most common characteristic mass shifts, i.e. $+16 \mathrm{Da}^{4,5,11}$. This methodology has been shown to be useful for individual amino acids, peptides, and small proteins but has not been utilized with larger proteins. Concern about direct detection methods exist due to potential oxidation from processing and the electrochemical nature of some ion sources such as electrospray ${ }^{12}$.

Recently, there have been some examples of using an oxidation-specific tag to label protein carbonyl groups and/or to identify the modification sites by mass spectrometry ${ }^{13-}$ 15. In these experiments, biotin hydrazide was used to tag the oxidized protein. There was some non-specific binding of the hydrazide to the protein ${ }^{13}$ and the endogenous biotinylation within cells can also be an issue ${ }^{15}$.

Here we present the development of a single method to visualize, quantitate, and site-specifically identify aldehyde and ketone oxidation sites on protein surfaces using an oxidation-dependent carbonyl-specific element-coded affinity tag (O-ECAT), ((S)-2-(4(2-aminooxy)-acetamido)-benzyl)-DOTA (AOD, Figure 1) in conjugation with nanoLC FT-ICR MS (nanoLiquid Chromatography Fourier Transform Ion Cyclon Resonance Mass Spectrometry). AOD has two key elements: 1) an aminooxy group that can form a covalent bond with aldehydes or ketones, and 2) a DOTA $(1,4,7,10$ tetraazacyclododecane- $N, N^{\prime}, N$ ', $N$ ", '-tetraacetic acid) metal-chelator moiety. AOD is water soluble and can be loaded with a wide choice of monoisotopic rare earths to generate a series of mass tags with large mass defects ${ }^{16}$ and nearly identical chromatographic behavior ${ }^{17}$. Confirmation of the labeling is achieved using Western blotting. Competitive ELISA is used to quantitate the AOD chelates per protein ${ }^{18}$. The 
protein is then digested with trypsin. Affinity purification is achieved using an immobilized antibody to M-DOTA, 2D12.5. Identification and quantitation are achieved through the unique mass signatures and elemental ratios observed by nanoLC-FTICR-MS. An algorithm is applied to the data that extracts the tagged peptides based on co-elution of the mass tags. Comparison of the observed masses to an in silico digest identifies the specific site of oxidation. In this paper, the oxidation sites of recombinant human serum albumin (rHSA), both in its native form and after FeEDTA-induced oxidation, are mapped onto an HSA crystal structure (pdb file: 1AO6, www.rcsb.org) ${ }^{19}$ as proof of concept. A variety of modified residues were identified and all map onto the surface of the protein. The methodology has also been used for site-specific quantitation between the two above samples. The quantitative results showed significant differences in increased oxidation between sites.

By studying the nature of protein oxidation on the site-specific level we hope to further the understanding of the mechanisms of oxidation related diseases and the role of free radical oxidation in biology.

\section{EXPERIMENTAL}

\section{Materials}

Recombinant human serum albumin, rare earth hexahydrate salts, and $p$ nitrophenyl phosphate were purchased from Sigma Aldrich (St. Louis, MO). The DOTA derivative, AOD was synthesized as described below. The anti-M-DOTA antibody 2D12.5 was a generous gift from Dr. David Goodwin, Palo Alto Veterans Administration Hospital (Palo Alto, CA). Goat anti-mouse lambda IgG-alkaline phosphatase conjugate 
was purchased from Southern Biotechnology (Birmingham, IL). Modified sequencing grade trypsin was purchased from Promega (Madison, WI). BCA reagents and aminolink plus resin were purchased from Pierce (Rockford, IL). 96-well plates were obtained from Fisher Scientific. Pure water $(18 \mathrm{M} \Omega \mathrm{cm})$ was used throughout.

\section{Chelate Synthesis}

ABD-tBu 4 , was synthesized as described previously ${ }^{20-22} .{ }^{1} \mathrm{H}$ NMR $(300 \mathrm{MHz}$, $\left.\mathrm{CDCl}_{3}\right) \delta 1.0-4.0(\mathrm{~m}, 63 \mathrm{H}), 6.39(\mathrm{~d}, J=8.7 \mathrm{~Hz}, 2 \mathrm{H}), 6.73(\mathrm{~d}, J=8.7 \mathrm{~Hz}, 2 \mathrm{H})$. ESI-MS: calcd $(\mathrm{M}+\mathrm{H})^{+} \mathrm{m} / \mathrm{z} 734.51$, found 734.50 .

(S)-2-(4-(2-aminooxy)acetamidobenzyl)-1,4,7,10-tetraazacyclododecane$\mathrm{N}, \mathrm{N}^{\prime}, \mathrm{N}^{\prime \prime}, \mathrm{N}^{\prime \prime \prime}$-tetraacetic acid (AOD). 2.60g N-Boc-aminoxyacetic acid was dissolved in a minimal volume of $\mathrm{N}, \mathrm{N}$-dimethylformamide (DMF) and brought to a final volume of $50 \mathrm{~mL}$ with $\mathrm{CH}_{2} \mathrm{Cl}_{2}$. The solution was cooled in an ice bath to $0^{\circ} \mathrm{C}$, and $1.04 \mathrm{~mL}$ of diisopropylcarbodiimide (DIPCDI) was added with stirring. After 30min the solvent was removed under vacuum and a solution of $1.00 \mathrm{~g} \mathrm{ABD-tBu} 4$ dissolved in $20 \mathrm{~mL} \mathrm{DMF}$ supplemented with $0.5 \mathrm{~mL}$ diisopropylethylamine was added at RT. The solution was stirred for $2 \mathrm{hr}$, after which $200 \mathrm{~mL}$ of a $1 \%$ solution of triethylamine (TEA) in water was added, and then extracted five times with $20 \mathrm{~mL}$ aliquots of ethylacetate. The organic fractions were combined, dried over sodium sulfate and brought to dryness under vacuum, providing (S)-2-(4-(2-N-Boc-aminooxy)acetamido-benzyl)-1,4,7,10tetraazacyclododecane- $\mathrm{N}, \mathrm{N}^{\prime}, \mathrm{N}^{\prime \prime}, \mathrm{N}^{\prime \prime \prime}$-tetraacetic acid tetra-tertbutyl ester in quantitative yield. The product was dissolved in neat trifluoracetic acid and stirred overnight under a light stream of nitrogen. The resulting light yellow oil was dissolved in water and lyophilized to give AOD in quantitative yield as a flocculent white solid. HPLC analysis 
of the product by UV absorbance at $280 \mathrm{~nm}$ indicated greater than $98 \%$ purity. ${ }^{1} \mathrm{H}$ NMR $\left(300 \mathrm{MHz}, \mathrm{CD}_{6} \mathrm{SO}\right) \delta 1.0-4.0(\mathrm{~m}, 27 \mathrm{H}), 4.16(\mathrm{~s}, 2 \mathrm{H}), 7.23(\mathrm{~d}, J=8.1 \mathrm{~Hz}, 2 \mathrm{H}), 7.65(\mathrm{~d}, J$ $=8.1 \mathrm{~Hz}, 2 \mathrm{H}), 8.31(\mathrm{~s}, 2 \mathrm{H}), 9.69(\mathrm{~s}, 4 \mathrm{H})$. ESI-MS: calcd $(\mathrm{M}+\mathrm{H})^{+} \mathrm{m} / z$ 583.27, found 583.26.

\section{Metallation}

AOD was metallated by combining the chelate with 1.8 equivalents of $\mathrm{M}-\mathrm{Cl}_{3}$, $35 \mathrm{mM}$ and $59 \mathrm{mM}$ respectively, in $0.1 \mathrm{M}$ ammonium acetate, $\mathrm{pH} 6.1$ for $2 \mathrm{hr}$ at $37^{\circ} \mathrm{C}$ before 1.8 equivalents of DTPA were added. Complete metallation was confirmed by LC-MS and the chelates were used without further purification.

\section{Protein Oxidation}

$592 \mu \mathrm{M}$ aliquots of rHSA, dialyzed into cleavage buffer [10mM MOPS, $120 \mathrm{mM}$ $\mathrm{NaCl}, 10 \mathrm{mM} \mathrm{MgCl}_{2}, 1 \mathrm{mM}$ EDTA, $\mathrm{pH}$ 7.9], were oxidized with 20mM iron (III) EDTA (FeEDTA) and $20 \mathrm{mM}$ ascorbate while the native control had no oxidants added. The oxidation reaction was mixed and allowed to proceed at RT for $15 \mathrm{~min}$ before being dialyzed into tagging buffer [100mM $\left.\mathrm{KH}_{2} \mathrm{PO}_{4}, 0.5 \mathrm{M} \mathrm{NaCl}, \mathrm{pH} 6.5\right]$.

\section{AOD Labeling}

Each sample of rHSA was then split into two aliquots and labeled overnight at RT with two different M-AOD, e.g. Tb and Ho. The reactions were then extensively dialyzed into 50mM HEPES, $\mathrm{pH}$ 7.5. Protein concentration was determined using the Pierce microBCA method. Aliquots were taken for the gels, blots, and ELISA before the remaining protein was reduced, alkylated with iodoacetamide, and trypsin digested. To achieve site-specific quantitation, the same procedure was used except one M-AOD 
aliquot from FeEDTA/ascorbate-oxidized rHSA was combined with a different M-AOD aliquot of native rHSA control after trypsin digestion.

To confirm that the tags were incorporated into the protein, samples were loaded onto duplicate Invitrogen $10-20 \%$ Tris-glycine gels and were run for $1.5 \mathrm{~h}$ at $125 \mathrm{~V}$ in Laemmli buffer [25 mM Tris, $192 \mathrm{mM}$ glycine, $0.1 \%$ SDS]. One gel was stained using SYPRO Ruby and imaged using the ChemXRS imager (Biorad). The duplicate gel was blotted onto a PDVF membrane in CAPS buffer [10 mM CAPS, 10\% methanol] for $1.5 \mathrm{~h}$ at $50 \mathrm{~V}$. The blot was then blocked with $5 \%$ non-fat milk in TBS $[24.8 \mathrm{mM}$ Tris, $137 \mathrm{mM}$ $\mathrm{NaCl}, 0.269 \mathrm{mM} \mathrm{KCl}, \mathrm{pH} 7.4$ ] overnight. The blot was rinsed 4x with TBST [TBS with $0.05 \%$ Tween-20]. A 1:5,000 dilution of the $1 \mathrm{mg} / \mathrm{mL}$ anti-M-DOTA antibody $2 \mathrm{D} 12.5 \mathrm{in}$ TBST, was added to the blot and allowed to incubate for $1 \mathrm{hr}$ at RT with vigorous mixing. The blot was then rinsed 4x with TBST and a 1:2,000 dilution of the secondary antibody in TBST, a goat anti-mouse lambda-AP conjugate, was added and allowed to incubate at $\mathrm{RT}$ for $1 \mathrm{hr}$ with vigorous mixing. The blot was then rinsed $3 \mathrm{x}$ with TBST and $1 \mathrm{x}$ with TBS before being developed with BCIP/NBT in $0.1 \mathrm{M}$ Tris $\mathrm{pH} 9.5,0.5 \mathrm{mM} \mathrm{MgCl}$. The western blot was visualized using an HP5490c scanner.

\section{Competitive ELISA}

A competitive ELISA was used to quantitate the tagging yield ${ }^{18}$. First, clear, highbinding plates were coated with 0.3 pmol of HSA-2-iminothiolane-Y-((S)-2-(4-(2-bromo)acetamido)-benzyl)-DOTA in $50 \mathrm{mM} \mathrm{Na}_{2} \mathrm{CO}_{3}\left(\mathrm{pH}\right.$ 9.6) and stored at $4{ }^{\circ} \mathrm{C}$ overnight. Wells were emptied and rinsed $3 \mathrm{x}$ with TBST. The wells were then blocked with $200 \mu \mathrm{L}$ of $1 \%$ bovine serum albumin in TBS, at $37^{\circ} \mathrm{C}$ for $2 \mathrm{hr}$. $25 \mu \mathrm{L}$ of competitor M-(S)-2-(4nitro-benzyl)-DOTA (M-NBD) or $25 \mu \mathrm{L}$ of the AOD-tagged protein, from concentrations 
of micromolar to femtomolar, were then added to the wells with $25 \mu \mathrm{L}$ of $2 \mathrm{nM}$ anti-MDOTA antibody 2D12.5. Each sample was done in triplicate and run on the same plate. The plate was incubated at RT for $1 \mathrm{hr}$ with mixing. The wells were rinsed $3 \mathrm{x}$ with TBST and then $50 \mu \mathrm{L}$ of 1:4,000 dilution of goat anti-mouse lambda-AP was added to all wells. The plate was again incubated at RT for $1 \mathrm{hr}$ with mixing. The plate was rinsed $3 \mathrm{x}$ with TBST and $1 \mathrm{x}$ with $10 \mathrm{mM}$ diethanolamine, $0.5 \mathrm{mM} \mathrm{MgCl}_{2}, \mathrm{pH} 9.5$. $200 \mu \mathrm{L}$ of a $1 \mathrm{mg} / \mathrm{mL}$ solution of $p$-nitrophenylphosphate in the diethanolamine solution was then added to the wells. The plate was read at $405 \mathrm{~nm}$ for $30 \mathrm{~min}$ at $\mathrm{RT}$, using a kinetic reading every minute.

\section{Trypsin Digestion}

The trypsin protocol was as follows: 1) denature and reduce protein with $5 \mathrm{M}$ urea, 0.125M HEPES, $\mathrm{pH} 7.5,28 \mathrm{mM}$ DTT (dithiothretiol) for $45 \mathrm{~min}$ at $37^{\circ} \mathrm{C} ; 2$ ) alkylate the cysteines by adding iodoacetamide to a final concentration of $56 \mathrm{mM}$ and incubating at $\mathrm{RT}$ for $20 \mathrm{~min}$ in the dark; 3) reduce the concentration of the urea to $1 \mathrm{M}$ using $50 \mathrm{mM}$ HEPES, $\mathrm{pH} 7.5$, and add $\mathrm{CaCl}_{2}$ to a final concentration of $1 \mathrm{mM}$; 4) add sequencing grade modified trypsin (1:50 wt:wt ratio) and incubate at $37^{\circ} \mathrm{C}$ overnight.

\section{Affinity Purification of AOD Peptides}

The 2D12.5 antibody was coupled to Pierce aminolink plus resin and used for the affinity purification, essentially as described ${ }^{17}$. Briefly, after the trypsin digestion, the two M-AOD sets for each sample were combined and loaded onto $200 \mu \mathrm{L} 2 \mathrm{D} 12.5$ aminolink resin that had been equilibrated with loading buffer [ $25 \mathrm{mM}$ triethylammonium acetate (TEAOAc), $\mathrm{pH}$ 7]. The column was then washed with 12 column volumes (CVs) each of (1) loading buffer, (2) loading buffer $+1 \mathrm{M} \mathrm{NaCl}, \mathrm{pH} 7$, (3) $0.5 \%$ acetic acid, $\mathrm{pH}$ 
2.8 , (4) 4M urea, and (5) $1 \mathrm{x}$ loading $+20 \%$ acetonitrile with $2 \mathrm{CVs}$ loading buffer wash between all the washes. The tagged peptides were then eluted with $20 \mathrm{CVs}$ of $50 \%$ acetonitrile $/ 0.4 \%$ trifluoroacetic acid. Elution fractions were combined and dried using a speed-vac.

\section{NanoLC-FTICR-MS Instrumentation}

The nano-flow liquid chromatography pumps used in this work were the first prototype of a pump and a 2D-nanoLC system developed by Eksigent Technologies (Livermore, CA). The development of the nanoLC-FTICR-MS platform for this analysis is the first implementation of an LC-MS system based on this technology. The nanospray tips were produced in-house from $75 \mu \mathrm{m}$ ID fused silica tubing using a Sutter Instruments Co. Model P2000 laser tip puller. The chromatographic stationary phase of $5 \mu \mathrm{m}$ Luna C18 (Phenomenex) was packed directly into the nanospray tip by bomb loading a slurry in $70 \%$ ethanol such that the nanospray tip and the chromatographic column are integrated with the column terminating at the approximately $15 \mu \mathrm{m}$ diameter nanospray tip.

The mass spectrometer is a 9.4Tesla Apex II Fourier Transform Ion Cyclotron Resonance Mass Spectrometer (Bruker, Waltham, MA) with a modified Apollo source. Only part of the Apollo source is used in the nanospray configuration. The drying gas heater has been modified to deliver drying gas temperatures up to about $400^{\circ} \mathrm{C}$ and is operated at $350^{\circ} \mathrm{C}$ here. The main purpose of this gas is to heat the glass capillary which serves as the vacuum interface to the mass spectrometer. The nanospray interface is a home-built system with the pulled glass capillary kept at ground potential through a liquid junction of a platinum wire with the solvent in a low dead-volume tee. The 
nanospray potential of approximately $2 \mathrm{kV}$ is delivered to the counter-electrode / sampling orifice of the mass spectrometer. On the original Apollo electrospray source the sampling orifice was on a flat surface and was approximately $0.5 \mathrm{~mm}$ in diameter. This has been modified such that the nanospray tip sees an approximately $3 \mathrm{~mm}$ entrance that is later reduced to $0.5 \mathrm{~mm}$. The primary potential that the nanospray tip sees is from an inverted cone that extends from the $3 \mathrm{~mm}$ orifice at a slightly obtuse angle. The nanospray tip is placed on-axis approximately $1 \mathrm{~cm}$ from the $0.5 \mathrm{~mm}$ orifice. This geometry allows for two important effects. The ions are forced to traverse a distance of approximately $1 \mathrm{~cm}$ of atmospheric pressure, effectively desolvating the ions, yet are also effectively entrained in the directed fluid dynamic flow into the mass spectrometer. Significant improvements in sensitivity and stability have been realized from this modification as this work progressed.

NanoLC-FTICR-MS Analysis

The AOD-tagged, digested, and affinity purified samples were analyzed by reversed phase nanoliquid chromatography-Fourier transform ion cyclotron resonance mass spectrometry (nanoLC-FTICR-MS) using the instrument described above. Affinity elutions from the 2D12.5 column were loaded onto an approximately $10 \mathrm{~cm}$ long $75 \mu \mathrm{m}$ ID in-house packed C18 column. The gradient of A (10mM ammonium acetate, $0.1 \%$ formic) to B ( $0.1 \%$ formic in $90 \%$ acetonitrile) was from $10-50 \%$ B over $40 \mathrm{~min}$. Column effluent was directly interfaced with a home-built nanospray source into a Bruker Apex II 9.4T FTMS. Six 256k transients were co-added every 0.1 minutes without quenching the accumulation hexapole between acquisitions resulting in nearly 100\% duty cycle. Spectra 
were acquired in broadband mode without internal mass calibration or software based correction for space charging effects.

\section{Data Analysis}

To simplify the analysis, the mass spectral information was deconvoluted using inhouse software based on isotopic mass differences to give $[\mathrm{M}+\mathrm{H}]$ ion masses. The spectra were zero-filled once and apodized before fast Fourier transformation and deconvolution. The masses of the tagged peptides were extracted from the data based on the characteristic mass difference between the two metal-AOD tags and co-elution of the tagged mass pairs. The tagged peptide masses were then compared to an in silico rHSA digest allowing for up to two missed cleavages, with variable cysteine alkylation, and adjustments for the possible oxidation and tagging modifications. Oxidized lysine, arginine, proline, threonine, histidine, and glutamic and aspartic acid were considered ${ }^{4-6,}$

23. For relative quantitation experiments, the transients for each co-eluting pair of masses were summed across the chromatographic peak before apodization and Fourier transformation. Relative quantitation was determined by a ratio of peak heights between the two metal-AOD peaks using the tallest peak in each isotopic cluster.

\section{RESULTS AND DISCUSSION}

\section{AOD Labeling}

Although the natural genetic code does not include aldehyde or ketone-containing amino acids, proteins generally exhibit some level of aldehyde or ketone content even in the absence of purposeful oxidation ${ }^{9,10,24,25}$. One of the many advantages of the O-ECAT AOD system is the availability of the 2D12.5 monoclonal antibody specific for a range of M-DOTA chelates ${ }^{18}$. This antibody was first used to confirm the covalent tagging of the 
protein by running a Western blot of the AOD-tagged proteins (Figure 2). There were two types of samples analyzed. The first sample was rHSA (recombinant human serum albumin) as purchased from Sigma, without additional processing or oxidation. Oxidations observed in this sample are residual from production or unintentional. This sample will be referred to as "control rHSA" or "control samples." The second sample analyzed was rHSA purchased from Sigma and then oxidized with FeEDTA, peroxide, and ascorbate as described above. This sample will be referred to as "FeEDTA and ascorbate oxidized rHSA" or "FeEDTA and ascorbate oxidized samples." In Figure 2 lane 1, rHSA with no added AOD tag shows no reactivity while both the tagged control samples and the tagged FeEDTA and ascorbate oxidized samples show distinct bands at the correct molecular weight for human serum albumin $(\sim 66 \mathrm{kD})$. The oxidized protein samples show an increased intensity of labeling versus the native control lanes, as expected. Note that the metal within the AOD does not affect the labeling efficiency as seen by the equal intensity Western bands. This is further confirmed by quantitative ELISA and peptide integration of the LC-MS data (data not shown).

The 2D12.5 antibody was then used to quantify the tagging yield of the M-AOD on both the control and FeEDTA and ascorbate oxidized samples using the competitive ELISA (Figure 3$)^{18}$. Each sample was done in triplicate and the $\operatorname{logEC} \mathrm{C}_{50}$ values of the protein curves were compared with the standard TbNBD curve. Figure 3 shows that the control sample had 1 in 16 proteins was labeled with M-AOD and the FeEDTA/ascorbate oxidized sample had 1 in 9 proteins labeled. The oxidation with FeEDTA and ascorbate increased the tagging yield by nearly two-fold. A similar two-fold increase in oxidation 
was also seen in human albumin oxidized with hydrogen peroxide and quantified with the DNPH blot method 9 .

\section{Identification of the Tagged Peptides}

A number of factors aid in the identification of the tagged peptides: (1) the M-AOD adds a mass tag with a large mass defect onto the modified peptide; (2) the specific reactivity of our tagging system for carbonyl-containing oxidation products; (3) the 2D12.5 monoclonal antibody affinity purification reduces the background of non-specific peptides; and (4) the high chromatographic resolution of the reversed phase nanoLC separation requires co-elution of mass pairs; (5) and the high mass resolution of the FTICR requires those mass pairs to meet the criteria defined by (1) above. The range of possible elemental compositions is dramatically reduced beyond a typical proteomic analysis or the direct LC-MS detection of oxidized peptides. In a direct detection method it is necessary to distinguish between an oxidized peptide and an unoxidized peptide or even a completely unexpected species or impurity. In our analysis we can confidently assume that all of the masses of interest at least contained a carbonyl group before derivitization and in all probability are aldehyde or ketone products of protein oxidation. Although the specificity of each step is not absolute, the method as a whole is highly specific. In this proof of principle application we have chosen to limit the scope of our work to a more easily understood system both to have a simple development platform and to understand some of the fundamentals of protein oxidation chemistry that are not yet well understood. This allows greater confidence in our results. In future work, as the complexity of the system increases the means to increase confidence in assignment such 
as tandem mass spectrometry or the use of internal mass standards with dual spray sources are well established.

Example LC-MS spectra are shown in Figures 4A, 4B, 4C and 4D. Figures 4A and 4C show two-dimensional plots of $\mathrm{m} / \mathrm{z}$ versus retention time for the rHSA sample and the FeEDTA and ascorbate oxidized sample tagged with Tb/HoAOD, respectively. Identical peptides tagged by the $\mathrm{Tb} / \mathrm{HoAOD}$ system can be seen as co-eluting mass pairs as seen in Figure 4B. Figure 4D displays a representative mass spectrum for a $\mathrm{Tb} / \mathrm{Ho}$ mass pair. As mentioned above the rare earths contain a mass defect that distinguishes the M-AOD peptides from background peptides; this mass defect is readily detected within the resolution of the $\mathrm{FTICR}^{16}$. The mass of $\mathrm{Tb}$ is $158.925 \mathrm{Da}$ while Ho has a mass of 164.930Da, yielding a mass difference of 6.005Da. The experimental deviation in this mass difference between the co-eluting pairs has been limited to $0.02 \mathrm{Da}$, while the experimental masses for the Tb/HoAOD pairs presented here are within $0.05 \mathrm{Da}$ of the theoretical masses, providing convincing resolution of the tagged peptides. A comparison of the isotopic distribution of the co-eluting peptide-tag pair allows identification of the charge state and high resolution masses for the parent peptides. In Figure $4 \mathrm{D}$, the $\mathrm{m} / \mathrm{z}$ difference between isotopes of 0.5 and between the isotopic clusters of 3 indicate that the tagged peptides are in the +2 charge state. This spectrum was found to correspond to the FGERAFK peptide where the arginine has been oxidized and tagged with M-AOD. Using this method, 20 tryptic peptides were identified in the control sample and 29 tryptic peptides (including 12 of the 20 control peptides) were identified in the FeEDTA/ascorbate oxidized sample (see Tables 1A and 1B). Some of the control peptides may not have been detected in the FeEDTA/ascorbate sample due to low 
abundance. Mixing one metal AOD from the control and one metal from the experiment, i.e. the relative quantitation experiments, is a more rigorous comparison of two sample sets. This eliminates concerns about the errors generated through sample handling.

A variety of residues, including lysine, arginine, proline, histidine, threonine, aspartic and glutamic acid, were found to be oxidized and tagged with this method. Also, all of the peptides are true tryptic peptides. A majority of the oxidized amino acids in the native protein are either lysine or arginine. These oxidation products have been seen both in radiolytic oxidation of peptides ${ }^{5}$ and in metal catalyzed oxidation of proteins ${ }^{6}$. Since the human serum albumin used in this study is a recombinant protein, it may have been oxidized in processing. We made every effort to minimize oxidation of control samples during our work. Metal contamination was reduced by using EDTA in the reaction buffers. Even when the rHSA is pre-treated with an excess of another aminooxy derivative, aminooxyacetic acid, the oxidation on the native protein is still detectable with the M-AOD system (data not shown). Robinson et al. showed that albumins from bovine, egg, and human all have background carbonyl reactivity to $\mathrm{DNPH}^{9}$. Notice that the presence of the M-AOD on a lysine or arginine normally results in a missed trypsin cleavage at that residue.

The methodology was validated by mapping the oxidation sites on an HSA crystal structure, $1 \mathrm{AO}^{19}$. The crystals for this structure were grown from pooled HSA and from HSA expressed in Pichia pastoris. Both sources yielded essentially the same triclinic structure, at a resolution of $2.5 \AA$. In this structure, the protein is approximately $80 \times 80 \mathrm{x}$ 30A. Note that both termini, residues 1-4 and 583-585 did not have clear electron density. 
For the recombinant serum albumin (Sigma) used in this work, the first residue at the Nterminus, aspartic acid, was removed during expression.

Out of the 20 peptides identified within the native rHSA sample, three contain oxidized amino acids within the LDELRDEGK sequence (residues 182-190). This sequence was found to be oxidized and tagged at the aspartic or glutamic acid, the arginine, and the lysine. Examination of the crystal structure of $\mathrm{HSA}^{19}$ reveals that these residues occur in the center of the protein in the bottom cleft as shown in Figure 6B. This position is not known to be a metal-binding site on albumin but albumin does have multiple metal-binding sites. Albumin is known to bind metal at its N-terminus and also at a position bridging His67 and His $247^{26}$. Only the oxidized arginine product of LDELRDEGK is seen in the FeEDTA/ascorbate oxidized sample.

In the FeEDTA/ascorbate sample, a larger variety of oxidized amino acids is seen. This sample also has a peptide that contains multiple oxidized amino acids, TPVSDR (residues 467-472), with the oxidized arginine seen in both the native and FeEDTA/ascorbate samples while the oxidized proline product was only seen in the FeEDTA/ascorbate sample. This peptide is also not in proximity to the reported metalbinding sites on HSA. It is located on the back of the protein, near the top (Figure 6B). Note that one oxidized amino acid residue, Thr566, is seen in two nested peptides, as (K)ETC*FAEEGKK and (K)ETCFAEEGK with the asterisk indicating an alkylated cysteine residue.

The oxidized amino acids are mapped onto an HSA crystal structure $1 \mathrm{AO}^{19}$ (www.rcsb.org) in Figures 5A and 5B. The oxidized amino acids are shown in red for definitively oxidized amino acids and in orange for those peptides with more than one 
candidate amino acid. The N-terminus is colored blue for reference. As expected, the modified oxidized residues map onto the surface of the protein. Also, more oxidized and M-AOD tagged peptides were observed in the FeEDTA/ascorbate oxidized sample. The oxidized amino acids appear to be randomly distributed on the protein surface.

\section{Site Specific Quantitation of Peptides}

Relative quantitation of FeEDTA/ascorbate-oxidized rHSA versus rHSA control was achieved in two parallel experiments using TbAOD and TmAOD tags. In the first experiment TbAOD was used exclusively in tagging the FeEDTA/ascorbate-oxidized rHSA oxidation sites and TmAOD was used exclusively to tag the control rHSA oxidation sites. These samples were then mixed for relative quantitation analysis. An identical experiment was run in parallel with the metal tags reversed, i.e. the TmAOD tag was used to tag the FeEDTA/ascorbate-oxidized rHSA oxidation sites and TbAOD was used to tag the control rHSA oxidation sites. The results of these experiments are presented in Table 2. The experimental error in these results come from the preparation and oxidation of the parallel experiments but also from the inherent inaccuracy of mass spectrometric based differential tagging internal quantitation experiments generally. In Figure $6 \mathrm{~A}$ and Figure $6 \mathrm{~B}$ the locations of these quantitative results are mapped to the surface of rHSA. Notice in the bottom of both figures that there are three lysine oxidation sites in close proximity in the bottom cleft visible in these views. Interestingly the YIC*ENQDSISSKLK peptide exhibits a six fold increase in oxidation where the other neighboring lysine-containing peptides exhibit only a two to three fold increase in oxidation. This is despite the less oxidized peptide having two lysine residues available for oxidation. This and the other variations in site preference detailed above demonstrate 
the importance of the site specific oxidation information gained from this methodology. Not only may site specific oxidation information help in our fundamental understanding of protein oxidation but could potentially serve as site specific oxidation biomarkers of disease. This may also help elucidate the mechanisms of disease and the role of protein oxidation in oxidation linked diseases.

\section{Conclusions}

We have validated the O-ECAT AOD system using the model protein rHSA to show that we can not only detect and quantify aldehyde and ketone groups on oxidized proteins but also identify specific oxidized residues on the protein. All observed oxidation sites mapped to the surface of the protein. Arginine and lysine residues appeared to be more readily oxidized to aldehyde/ketone end products than the other amino acids observed. This is in agreement with the work by Stadtman et al. which showed that oxidized lysine, arginine, and proline residues are the major products of metal-catalyzed oxidation ${ }^{6}$. The quantitative results exhibited oxidation site preference that appeared independent of the oxidized residue. We expect that this general methodology can be extended to study disease-related oxidation. Given the site specificity observed here we expect that the site specific information this method provides will be useful in understanding the biochemical mechanisms of such diseases. In the process of such studies, diagnostic site specific oxidation biomarkers may also be found. We are currently extending method to study protein-protein interactions using the tethered iron chelate FeBABE to oxidatively tag protein binding partners. Further exploration on the use of the multiplexing of M-AOD, using up to 7 monoisotopic metals, is also planned. 


\section{Acknowledgements}

We thank Mark Scalf and Yi-Hwa Hwang for their help in the development of the work. We thank Laurel Beckett and Judy Li for helpful discussions and statistical analysis of the data. We thank Gary Kruppa for providing elements of the data analysis software. We also thank Mark McCoy for assistance with data processing. This work was supported by National Institutes of Health research grants GM25909 to CFM and GM049077 to CBL and the Department of Energy Advanced Study Program to NLY. Portions of this work were performed under the auspices of the U.S. Department of Energy by University of California, Lawrence Livermore National Laboratory under Contract W-7405-Eng-48.

\section{SUPPORTING INFORMATION PARAGRAPH (Word Style}

“TE_Supporting_Information"). A brief statement in nonsentence format listing the contents of material placed here should be included at the end of the manuscript as a separate section titled Supporting Information Available. The contents of Supporting Information may include the following: (1) large tables, (2) extensive figures, (3) lengthy experimental procedures, (4) mathematical derivations, (5) analytical and spectral characterization data, (6) molecular modeling coordinates, (7) modeling programs, (8) crystallographic information files (CIF), (9) instrument and circuit diagrams, (10) and expanded discussions of peripheral findings. For complete instructions on how to prepare this material for publication, check the Guide, Notes, Notice, or Instructions for Authors that appear in each publication's first issue of the year and on the World Wide Web at http://pubs.acs.org. 
References

(1) Dalle-Donne, I.; Giustarini, D.; Colombo, R.; Rossi, R.; Milzani, A. Trends in Molecular Medicine 2003, 9, 169-176.

(2) Butterfield, D. A. Brain Research 2004, 1000, 1-7.

(3) Levine, R. L. Free Radical Biology and Medicine 2002, 32, 790-796.

(4) Xu, G. Z.; Chance, M. R. Analytical Chemistry 2004, 76, 1213-1221.

(5) Xu, G. Z.; Takamoto, K.; Chance, M. R. Analytical Chemistry 2003, 75, 69957007.

(6) Requena, J. R.; Chao, C.-C.; Levine, R. L.; Stadtman, E. R. PNAS 2001, 98, 69-74.

(7) Meade, S. J.; Miller, A. G.; Gerrard, J. A. Bioorganic \& Medicinal Chemistry 2003, 11, 853-862.

(8) Robinson, C. E.; Keshavarzian, A.; Pasco, D. S.; Frommel, T. O.; Winship, D. H.; Holmes, E. W. Analytical Biochemistry 1999, 266, 48-57.

(9) Fagan, J. M.; Sleczka, B. G.; Sohar, I. The International Journal of Biochemistry \& Cell Biology 1999, 31, 751-757.

(10) Sharp, J. S.; Becker, J. M.; Hettich, R. L. Analytical Chemistry 2004, 76, 672-683.

(11) Davies, M. J.; Fu, S. L.; Wang, H. J.; Dean, R. T. Free Radical Biology \& Medicine 1999, 27, 1151-1163.

(12) Anderson, L. B.; Ouellette, A. J. A.; Eaton-Rye, J.; Maderia, M.; MacCoss, M. J.; Yates, J. R.; Barry, B. A. Journal of the American Chemical Society 2004, 126, 8399-8405.

(13) Mirzaei, H.; Regnier, F. Analytical Chemistry 2005, 77, 2386-2392.

(14) Yoo, Y. S.; Regnier, F. E. Electrophoresis 2004, 25, 1334-1341.

(15) Hall, M. P.; Ashrafi, S.; Obegi, I.; Petesch, R.; Peterson, J. N.; Schneider, L. V. Journal of Mass Spectrometry 2003, 38, 809-816.

(16) Whetstone, P. A.; Butlin, N. G.; Corneillie, T. M.; Meares, C. F. Bioconjugate Chem 2004, 15, 3 - 6.

(17) Corneillie, T. M.; Whetstone, P. A.; Fisher, A. J.; Meares, C. F. Journal of the American Chemical Society 2003, 125, 3436-3437.

(18) Sugio, S.; Kashima, A.; Mochizuki, S.; Noda, M.; Kobayashi, K. Protein Engineering 1999, 12, 439-446.

(19) Moi, M.; Meares, C. F.; DeNardo, S. J. Journal of American Chemical Society 1988, 110, 6266-6267.

(20) Corson, D. T.; Meares, C. F. Bioconjugate Chemistry 2000, 11, 292-299.

(21) Takenouchi, K.; Tabe, M.; Watanabe, K.; Hazato, A.; Kato, Y.; Shionoya, M.; Koike, T.; Kimura, E. Journal of Organic Chemistry 1993, 58, 6895-6899.

(22) Taborsky, G. Biochemistry 1973, 12, 1341-1348.

(23) Choi, J.; Malakowsky, C. A.; Talent, J. M.; Conrad, C. C.; Carroll, C. A.; Weintraub, S. T.; Gracy, R. W. Biochimica et Biophysica Acta (BBA) - Molecular Basis of Disease 2003, 1637, 135-141.

(24) Choi, J.; Conrad, C. C.; Dai, R.; Malakowsky, C. A.; Talent, J. M.; Carroll, C. A.; Weintraub, S. T.; Gracy, R. W. PROTEOMICS 2003, 3, 73-77.

(25) Sokolowska, M.; Krezel, A.; Dyba, M.; Szewczuk, Z.; Bal, W. European Journal of Biochemistry 2002, 269, 1323-1331. 
SYNOPSIS TOC (Word Style "SN_Synopsis_TOC"). If you are submitting your paper to a journal

that requires a synopsis graphic and/or synopsis paragraph, see the Guide, Notes, Notice, or Instructions

for Authors that appear in each publication's first issue of the year and the journal's homepage for a

description of what needs to be provided and for the size requirements of the artwork. 
Figure 1. Oxidation-specific Element-Coded Affinity Tag (O-ECAT): AOD, (((S)-2-(4(2-aminooxy)-acetamido)-benzyl)-1,4,7,10-tetraazacyclododecane- $N, \quad N^{\prime}, \quad N^{\prime \prime}, \quad N^{\prime \prime \prime}$ tetraacetic acid.<smiles></smiles>

Figure 2. Western blot confirmation of the M-AOD tagging of native and FeEDTA/ascorbate oxidized rHSA. Lane 1: rHSA, lane 2: rHSA TbAOD, lane 3: rHSA HoAOD, lanes 4 \& 5: rHSA oxidized with FeEDTA and ascorbate, TbAOD and HoAOD, respectively. Equal amounts of rHSA were loaded into lanes 1-5.

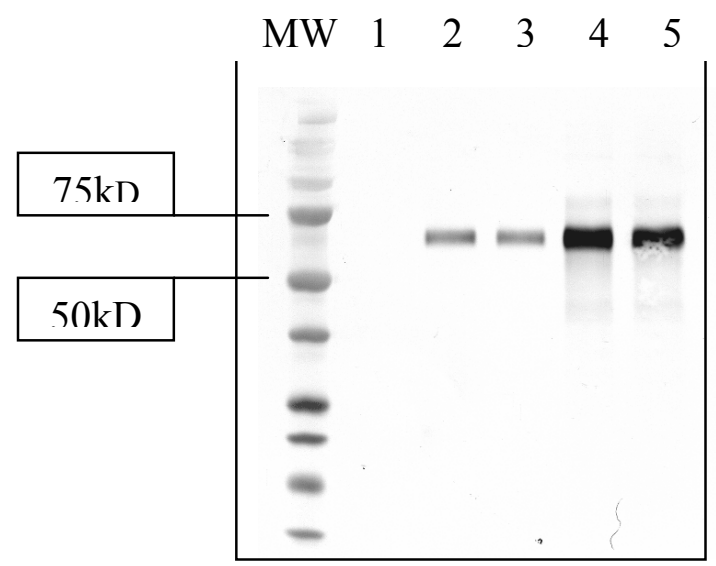

Figure 3. Competitive DOTA ELISA quantifying the tagging yield on the control rHSA TbAOD and the rHSA oxidized with FeEDTA and ascorbate, rHSAoxTbAOD. The concentration on the horizontal axis represents either protein concentration (moles/liter) 
or competitor TbNBD concentration (moles/liter). Each data set was done in triplicate with the error bars showing one standard deviation.

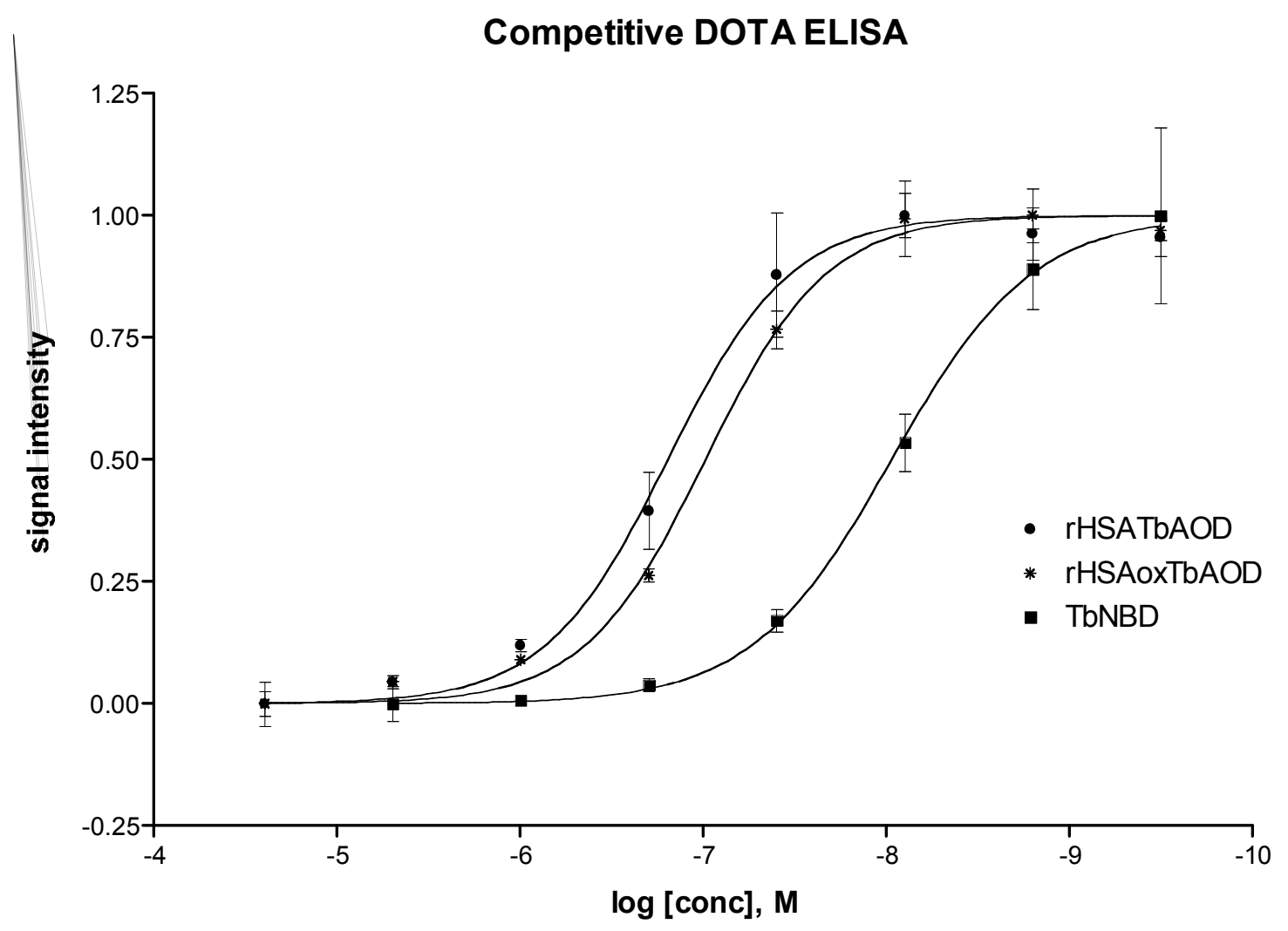

Figure 4. LC-MS spectra showing the co-eluting M-AOD tagged peptide pairs.

A. A two-dimensional spectrum showing $\mathrm{m} / \mathrm{z}$ versus retention time for an affinitypurified rHSA sample tagged with TbAOD and HoAOD. 


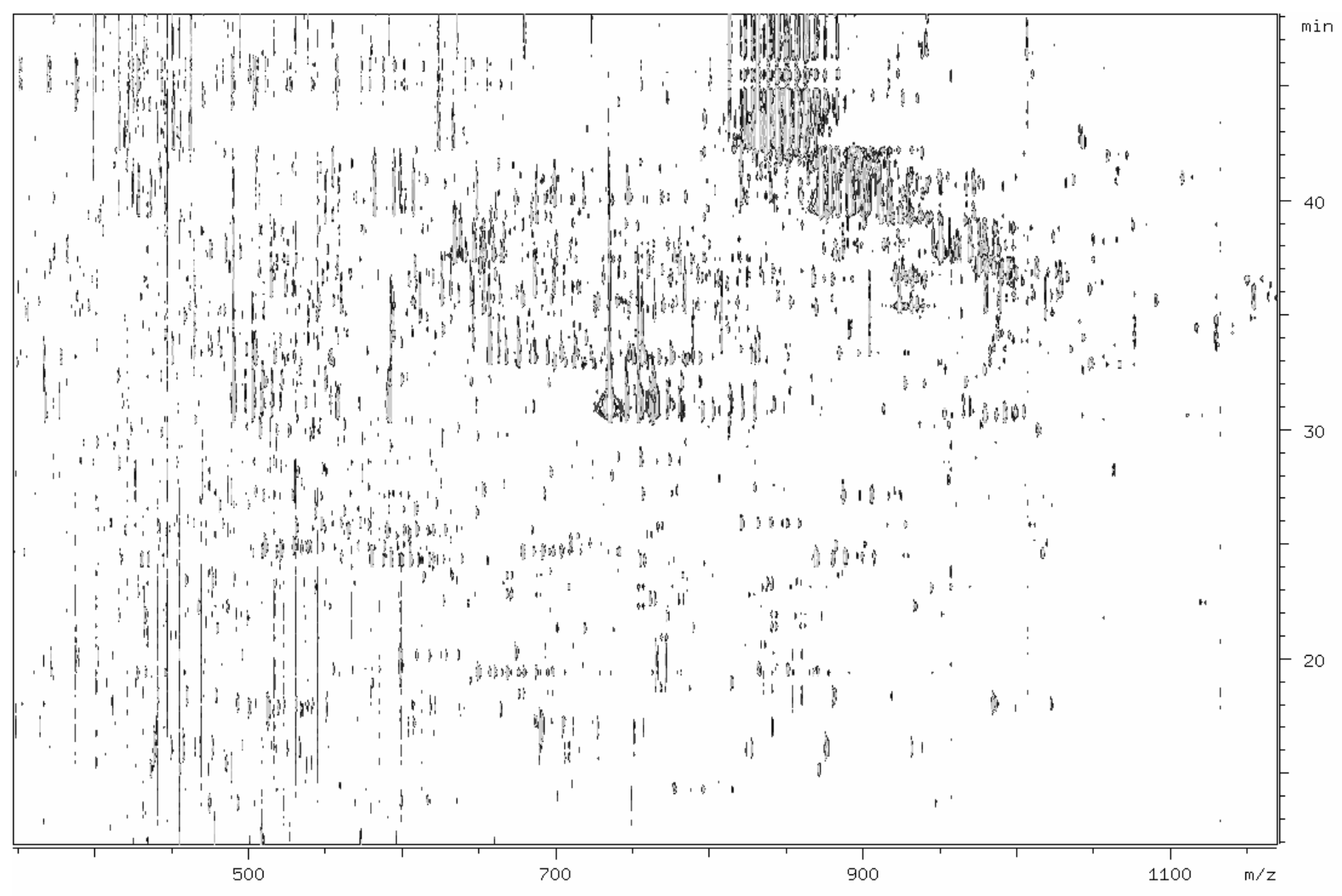

Figure 4. LC-MS spectra showing the co-eluting M-AOD tagged peptide pairs.

B. An enlargement of the two-dimensional spectrum showing $\mathrm{m} / \mathrm{z}$ versus retention time for an affinity-purified rHSA sample tagged with TbAOD and HoAOD from Fig. 4A 


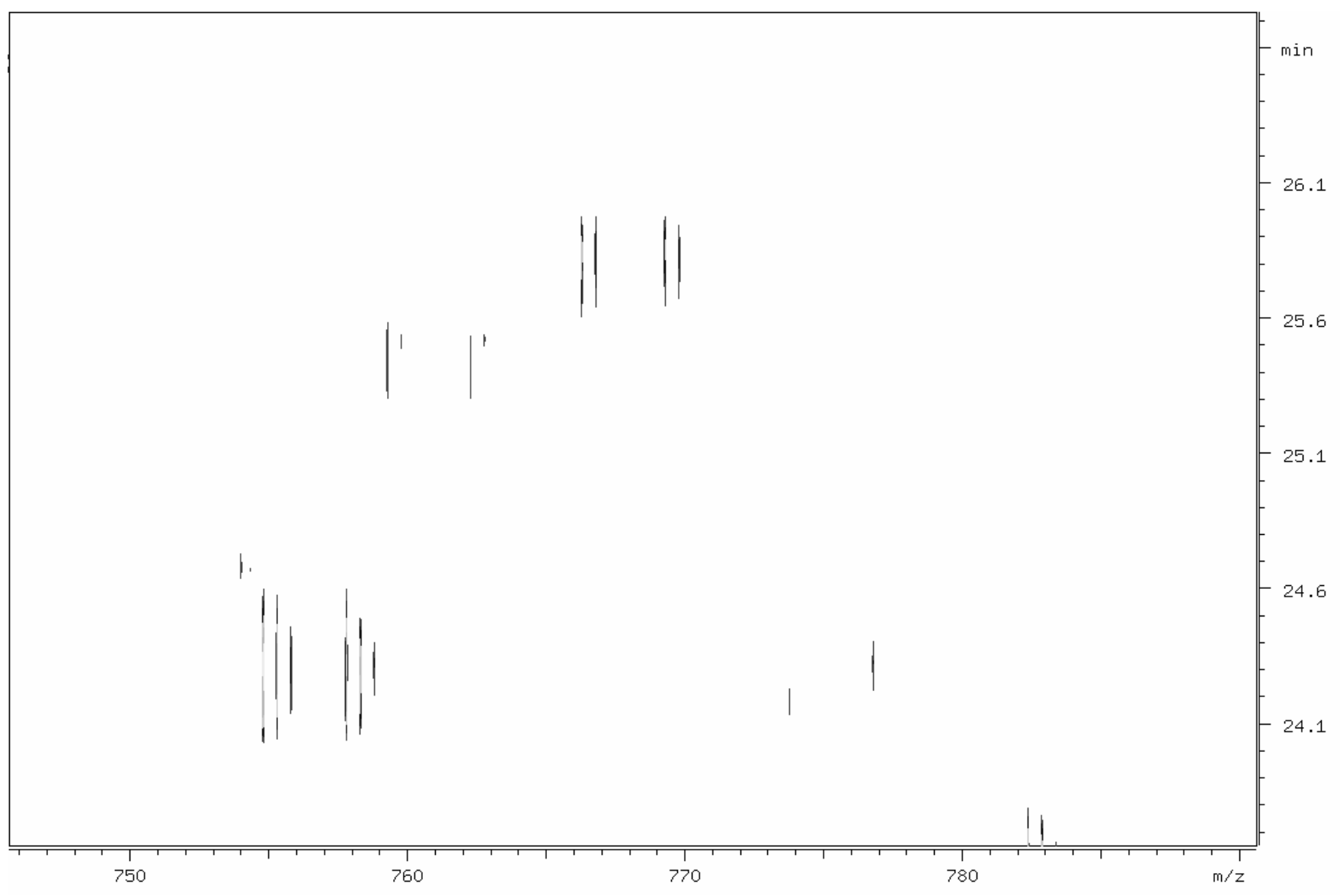

Figure 4. LC-MS spectra showing the co-eluting M-AOD tagged peptide pairs. 
C. A two-dimensional spectrum showing $\mathrm{m} / \mathrm{z}$ versus retention time for an affinitypurified FeEDTA/ascorbate oxidized rHSA sample tagged with TbAOD and HoAOD.

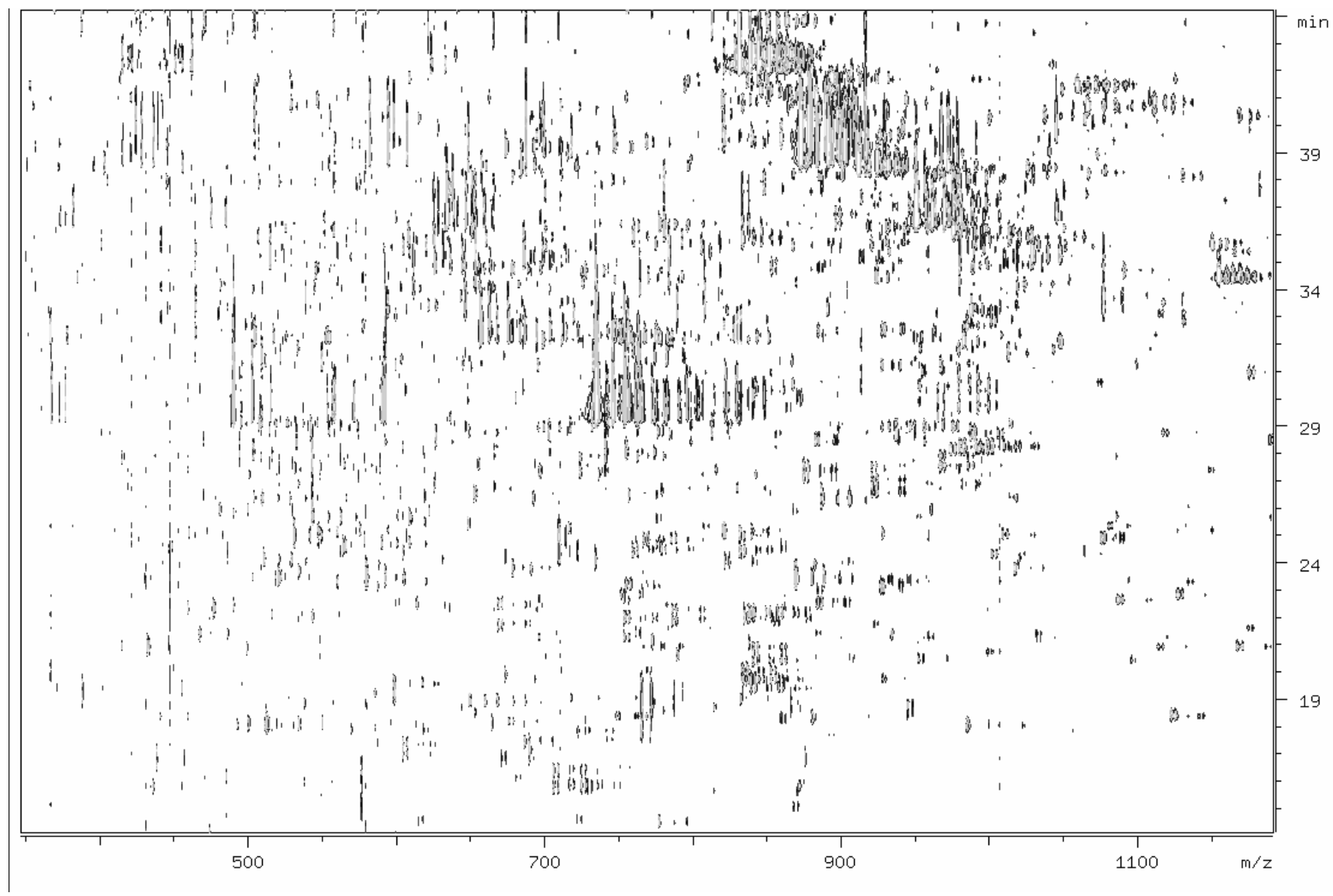

Figure 4. LC-MS spectra showing the co-eluting M-AOD tagged peptide pairs. 
D. FTMS spectrum showing a doubly charged mass pair. The peaks shown here correspond to the peptide, FGERAFK, with the arginine oxidized and tagged with TbAOD and HoAOD.

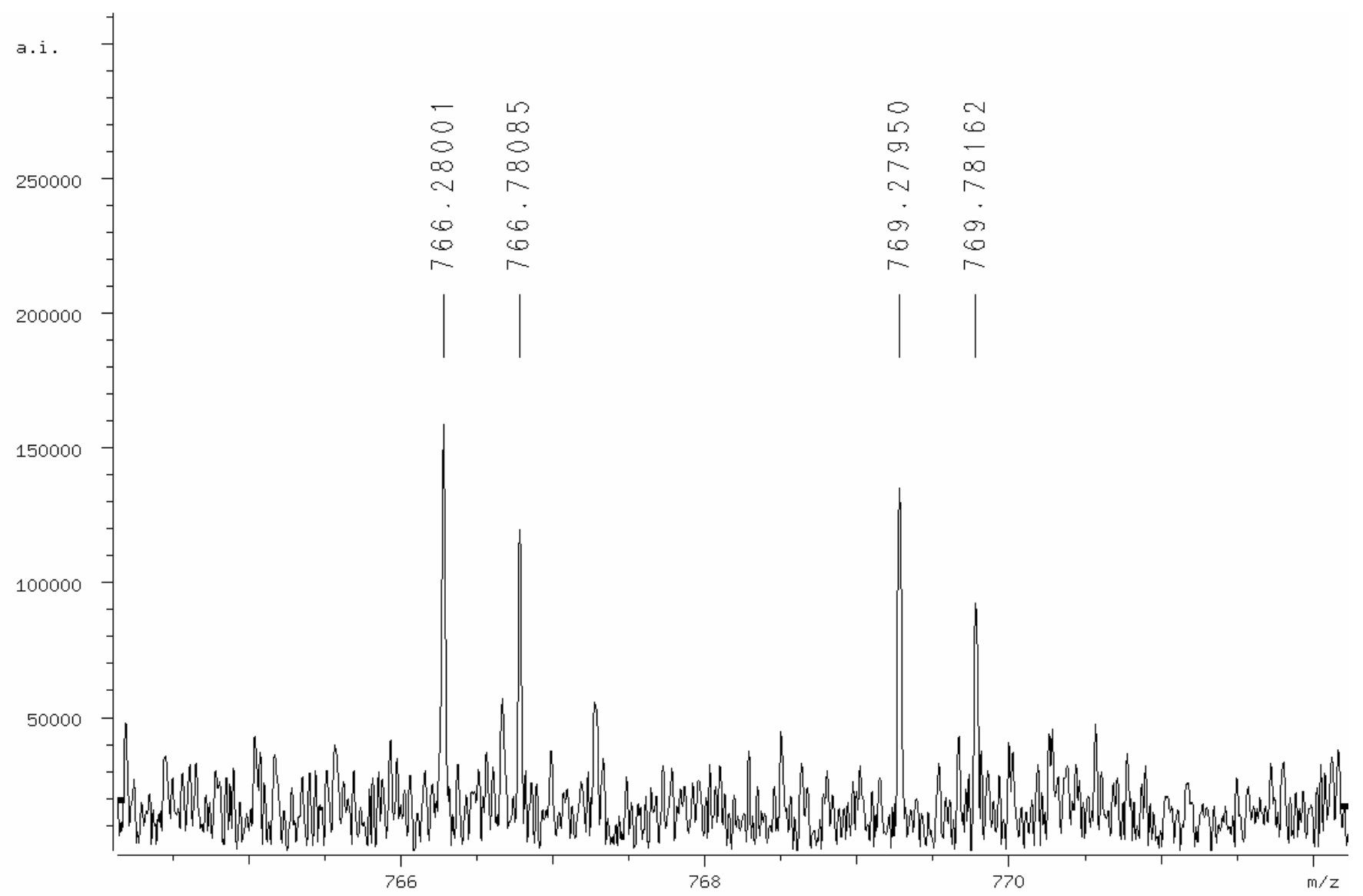

Figure 5. Oxidized and tagged peptides mapped onto the crystal structure of HSA (pdb file: 1AO6, www.rcsb.org). The oxidized amino acids are shown in red for definitive candidates and in orange for those peptides with more than one candidate amino acid. The N-terminus, on the front of the protein, is colored in blue for reference. The front view is shown to the left, rotating the protein $180^{\circ}$ yields the back view, shown to the right. 
A. rHSA control: peptides identified on the native protein.

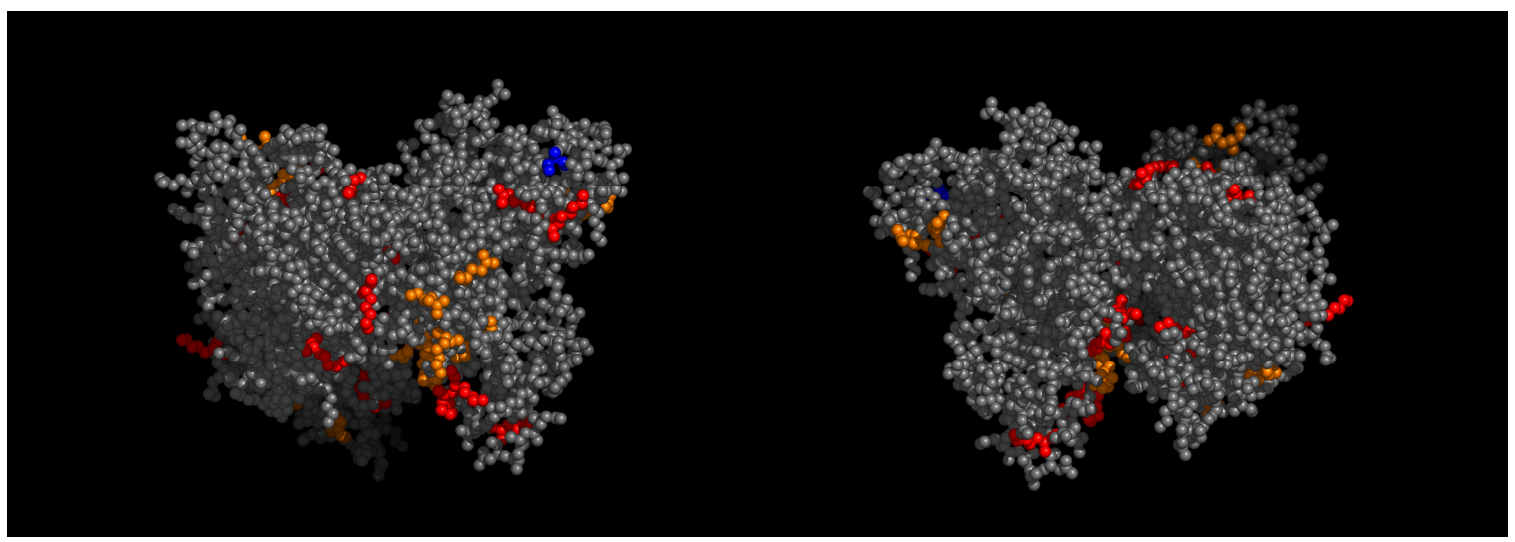

B. FeEDTA/ascorbate-Mediated Oxidation: peptides identified on the FeEDTA/ascorbate oxidized protein.

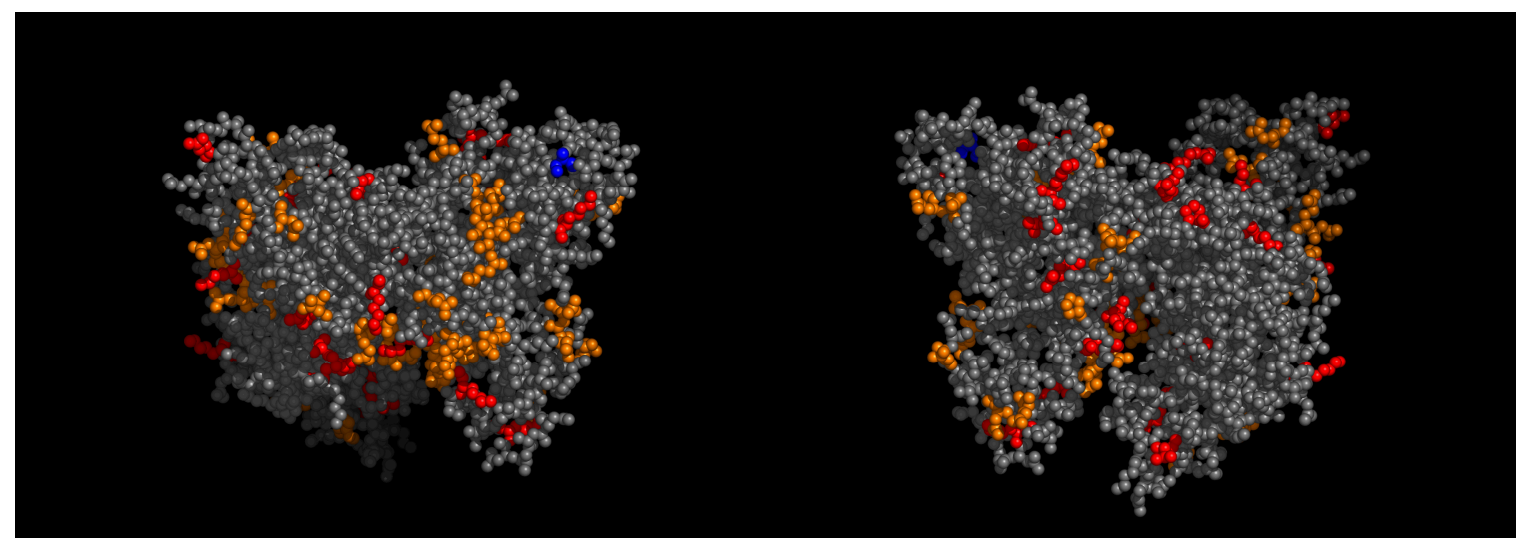


Figure 6. Quantitation data from Table 2 mapped onto the crystal structure of rHSA (pdb file: 1AO6, www.rcsb.org). The oxidized amino acids are shown in red for definitive candidates and in orange for those peptides with more than one candidate amino acid. The N-terminus, on the front of the protein, is colored in blue for reference. The front view is shown to the left, rotating the protein $180^{\circ}$ yields the back view, shown to the right. The amount of increase seen in the FeEDTA/ascorbate/peroxide samples over the control are indicated for each peptide.

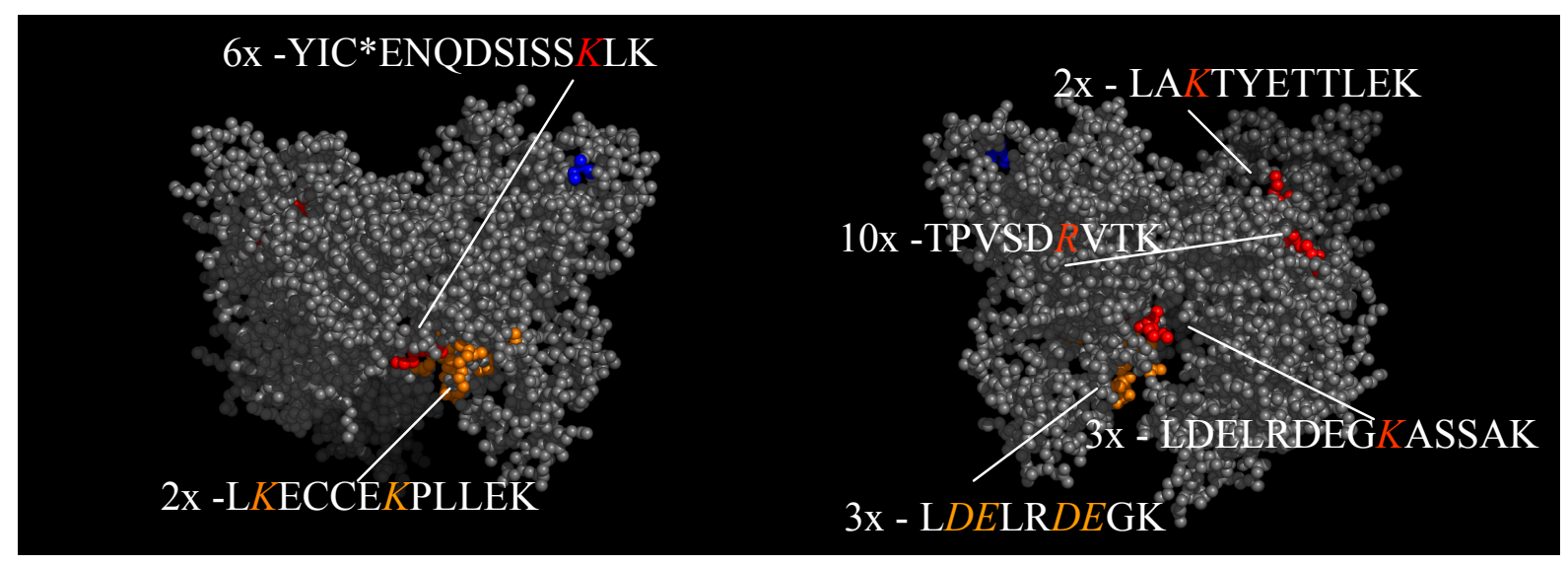

Table 1A. Oxidized peptides labeled with M-AOD identified on native rHSA. 
The sequence of the identified peptide, along with the preceding amino acid residue, is listed with the oxidized, tagged residue indicated in bold while alkylated cysteines are indicated with asterisks. For peptides with more than one possible modified amino acid, the all candidate amino acids are listed.

\begin{tabular}{|c|c|c|c|c|c|}
\hline Sequence & $\begin{array}{c}\text { Modified } \\
\text { AA }\end{array}$ & $\begin{array}{c}\text { Sequence } \\
\#\end{array}$ & $\begin{array}{c}\text { Theoretical } \\
\text { MW }\end{array}$ & $\begin{array}{c}\text { Observed } \\
\text { MW }\end{array}$ & $\begin{array}{c}\text { Error } \\
\text { (ppm) }\end{array}$ \\
\hline (K)AAC*LLPKLDELRDEGK & Lys & $175-190$ & 2547.0878 & 2547.0575 & 12 \\
\hline (K)ATKEQLK & Lys & $539-545$ & 1536.6024 & 1536.5821 & 13 \\
\hline (K)C*ASLQKFGER & Lys & $200-209$ & 1914.7134 & 1914.6824 & 16 \\
\hline (K)ERQIKK & Arg & $520-525$ & 1478.5970 & 1478.5774 & 13 \\
\hline (K)FGERAFK & Arg & $206-212$ & 1531.5548 & 1531.5360 & 12 \\
\hline (R)FKDLGEENFK & Lys & $11-20$ & 1945.7297 & 1945.6992 & 16 \\
\hline (R)FPKAEFAEVSK & Lys & $223-233$ & 1971.7818 & 1971.7495 & 16 \\
\hline (K)HPEAKR & Lys & $440-445$ & 1456.5299 & 1456.5101 & 14 \\
\hline (R)LAKTYETTLEK & Lys & $349-359$ & 2015.8291 & 2015.7980 & 15 \\
\hline (K)LDELRDEGK & Asp/Glu & $182-190$ & 1764.6882 & 1764.6629 & 14 \\
\hline (K)LDELRDEGK & Arg & $182-190$ & 1751.6454 & 1751.6189 & 15 \\
\hline (K)LDELRDEGKASSAK & Lys & $182-195$ & 2237.9004 & 2237.8540 & 21 \\
\hline (R)LKCASLQK & Lys & $198-205$ & 1609.6374 & 1609.5969 & 25 \\
\hline (K)LKECCEKPLLEK & Lys & $275-286$ & 2265.9213 & 2265.8770 & 20 \\
\hline (K)LVNEVTEFAK & Glu & $42-51$ & 1839.7607 & 1839.7334 & 15 \\
\hline (R)QIKK & Lys & $522-525$ & 1235.4750 & 1235.4582 & 14 \\
\hline (K)SEVAHRFK & Arg & $5-12$ & 1650.6243 & 1650.6003 & 15 \\
\hline (K)TPVSDRVTK & Arg & $467-475$ & 1679.6607 & 1679.6368 & 14 \\
\hline (K)TYETTLEK & Glu & $352-359$ & 1674.6341 & 1674.6096 & 15 \\
\hline (K)YIC*ENQDSISSK & Asp/Glu & $263-274$ & 2133.7877 & 2133.7462 & 19 \\
\hline
\end{tabular}


Table 1B. Oxidized peptides labeled with M-AOD identified on FeEDTA/ascorbateoxidized rHSA.

The sequence of the identified peptide, along with the preceding amino acid residue, is listed with the oxidized, tagged residue indicated in bold while alkylated cysteines are indicated with asterisks. For peptides with more than one possible modified amino acid, the all candidate amino acids are listed.

\begin{tabular}{|c|c|c|c|c|c|c|}
\hline Sequence & $\begin{array}{c}\text { Modified } \\
\text { AA } \\
\end{array}$ & $\begin{array}{c}\text { Sequence } \\
\text { number }\end{array}$ & $\begin{array}{c}\text { Present } \\
\text { in }\end{array}$ & $\begin{array}{c}\text { Theoretical } \\
\text { MW }\end{array}$ & $\begin{array}{c}\text { Observed } \\
\text { MW } \\
\end{array}$ & $\begin{array}{l}\text { Error } \\
(\mathrm{ppm})\end{array}$ \\
\hline (K)ADDKETCFAEEGK & Asp/Glu & $561-573$ & & 2189.7775 & 2189.7574 & 9 \\
\hline (K)AEFAEVSK & Asp/Glu & $226-233$ & & 1570.5867 & 1570.5804 & 4 \\
\hline (K)ATKEQLK & Lys & $539-545$ & $\mathrm{Y}$ & 1536.6024 & 1536.5913 & 7 \\
\hline (K)AVMDDFAAFVEK & Asp/Glu & $546-557$ & & 2032.7804 & 2032.7904 & -5 \\
\hline$(\mathrm{K}) \mathrm{C}^{*} \mathrm{ASLQKFGER}$ & Lys & $200-209$ & $\mathrm{Y}$ & 1914.7134 & 1914.7061 & 4 \\
\hline$(\mathrm{K}) \mathrm{C}^{*} \mathrm{C}^{*} \mathrm{AAADPHEC} * \mathrm{YAK}$ & Asp/Glu & $360-372$ & & 2242.7439 & 2242.7130 & 14 \\
\hline (K)DDNPNLPR & Pro & $107-114$ & & 1676.5992 & 1676.5863 & 8 \\
\hline (K)ECCEKPLLEK & Asp/Glu & $277-286$ & & 1995.7634 & 1995.7441 & 10 \\
\hline (K)ETC*FAEEGKK & Thr & $565-574$ & & 1902.6657 & 1902.6537 & 6 \\
\hline (K)ETCFAEEGK & Thr & $565-573$ & & 1717.5493 & 1717.5282 & 12 \\
\hline (R)ETYGEMADCCAK & Asp/Glu & $82-93$ & & 2124.679127 & 2124.6572 & 10 \\
\hline (R)ETYGEMADC*C*AKQEPER & Lys & $82-98$ & & 2792.9556 & 2792.9229 & 12 \\
\hline (K)FGERAFK & Arg & $206-211$ & $\mathrm{Y}$ & 1531.5548 & 1531.5506 & 3 \\
\hline (R)FKDLGEENFK & Lys & $11-20$ & $\mathrm{Y}$ & 1945.7297 & 1945.7292 & 0.3 \\
\hline (R)FPKAEFAEVSK & Lys & $223-233$ & $\mathrm{Y}$ & 1971.7818 & 1971.7767 & 3 \\
\hline$(\mathrm{K}) \mathrm{HKPK}$ & His & $535-538$ & & 1177.4331 & 1177.4288 & 4 \\
\hline (R)LAKTYETTLEK & Lys & $349-359$ & $\mathrm{Y}$ & 2015.8291 & 2015.8243 & 2 \\
\hline (K)LDELRDEGK & Arg & $182-190$ & $\mathrm{Y}$ & 1751.6454 & 1751.6360 & 5 \\
\hline (K)LKECCEKPLLEK & Lys & $275-286$ & $\mathrm{Y}$ & 2265.9213 & 2265.9095 & 5 \\
\hline (K)LVNEVTEFAK & Asp/Glu & $42-51$ & $\mathrm{Y}$ & 1839.7607 & 1839.7554 & 3 \\
\hline (R)NECFLQHK & Asp/Glu & 99-106 & & 1708.6232 & 1708.6457 & -13 \\
\hline (K)QEPERNEC*FLQHK & Arg & $94-106$ & & 2391.8994 & 2391.8819 & 7 \\
\hline (K)QTALVELVK & Thr & $526-534$ & & 1704.7286 & 1704.7038 & 15 \\
\hline (K)TPVSDR & Pro & $467-472$ & & 1410.4977 & 1410.4861 & 8 \\
\hline (K)TPVSDRVTK & Arg & $467-475$ & $\mathrm{Y}$ & 1679.6607 & 1679.6490 & 7 \\
\hline (K)TYETTLEK & Asp/Glu & $352-359$ & $\mathrm{Y}$ & 1674.634127 & 1674.6219 & 7 \\
\hline (K)VFDEFKPLVEEPQNLIK & Asp/Glu & $373-389$ & & 2735.2410 & 2735.2111 & 11 \\
\hline (K)VHTEC*C*HGDLLECADDR & Asp/Glu & $241-257$ & & 2776.9832 & 2776.9671 & 6 \\
\hline (K)YIC*ENQDSISSK & Asp/Glu & $263-274$ & $\mathrm{Y}$ & 2133.7877 & 2133.7689 & 9 \\
\hline
\end{tabular}




\begin{tabular}{|l|l|l|l|l|l|l|}
\hline$(\mathrm{K}) \mathrm{YIC} *$ ENQDSISSKLK & Lys & $263-276$ & & 2403.9456 & 2403.9326 & 5 \\
\hline
\end{tabular}


Table 2. Relative quantitation of FeEDTA/ascorbate-oxidized rHSA versus rHSA control, native oxidized peptides.

In column 1 the corresponding peptide is identified with the oxidized residues or candidate oxidized residues in bold and carboxymethylation of cysteine indicated with an asterix. In column 2 integrated intensity ratios of $\mathrm{Tb}$ signal to $\mathrm{Tm}$ signal where $\mathrm{Tb}$ was used in tagging the FeEDTA/ascorbate-oxidized rHSA oxidation sites and Tm was used to tag the control rHSA oxidation sites. In column 3 integrated intensity ratios of $\mathrm{Tm}$ signal to $\mathrm{Tb}$ signal where $\mathrm{Tm}$ was used in tagging the FeEDTA/ascorbate-oxidized rHSA oxidation sites and $\mathrm{Tb}$ was used to tag the control rHSA oxidation sites. In column 4 the average of columns 2 and 3 is given.

\begin{tabular}{|c|c|c|c|}
\hline Peptide & $\begin{array}{c}\text { FeEDTA/Native } \\
(\mathrm{Tb} / \mathrm{Tm})\end{array}$ & $\begin{array}{c}\text { FeEDTA/Native } \\
(\mathrm{Tm} / \mathrm{Tb})\end{array}$ & $\begin{array}{c}\text { FeEDTA/Native } \\
\text { (Average) }\end{array}$ \\
\hline LDELRDEGK & 2.5 & 3.2 & 2.9 \\
\hline TPVSDRVTK & 11.5 & 8.0 & 9.8 \\
\hline LDELRDEGKASSAK & 1.6 & 3.5 & 2.6 \\
\hline LKECCEKPLLEK & 1.6 & 2.5 & 2.1 \\
\hline LAKTYETTLEK & 2.8 & 1.7 & 2.3 \\
\hline YIC"ENQDSISSKLK & 5.3 & 5.7 & 5.5 \\
\hline
\end{tabular}

